University of New Hampshire

University of New Hampshire Scholars' Repository

Use of waveform lidar and hyperspectral sensors to assess selected spatial and structural patterns associated with recent and repeat disturbance and the abundance of sugar maple (Acer saccharum Marsh.) in a temperate mixed hardwood and conifer forest.

Jeanne E. Anderson

University of New Hampshire - Main Campus

Mark J. Ducey

University of New Hampshire, mark.ducey@unh.edu

Andrew J. Fast

University of New Hampshire - Main Campus, Andrew.Fast@unh.edu

Mary E. Martin

University of New Hampshire - Main Campus, mary.martin@unh.edu

Follow this and additional works at: https://scholars.unh.edu/nren_facpub

I I cie C. Lepine

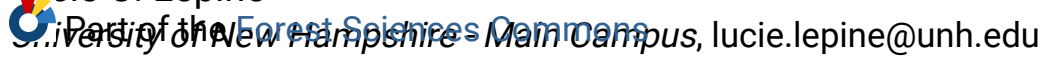

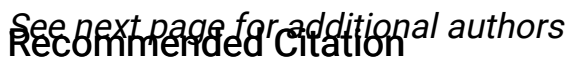

nderson, J.E., Ducey, M.J., Fast, A., Martin, M.E., Lepine, L., Smith, M.-L., Lee, T.D., Dubayah, R.O., Hofton, M.A., Hyde, P., Peterson, B.E., Blair, J.B. Use of waveform lidar and hyperspectral sensors to assess selected spatial and structural patterns associated with recent and repeat disturbance and the abundance of sugar maple (Acer saccharum Marsh.) in a temperate mixed hardwood and conifer forest. (2011) Journal of Applied Remote Sensing, 5 (1), art. no. 053504, . doi: 10.1117/1.3554639

This Article is brought to you for free and open access by the Natural Resources and the Environment at University of New Hampshire Scholars' Repository. It has been accepted for inclusion in Natural Resources and the Environment Scholarship by an authorized administrator of University of New Hampshire Scholars' Repository. For more information, please contact Scholarly.Communication@unh.edu. 


\section{Authors}

Jeanne E. Anderson, Mark J. Ducey, Andrew J. Fast, Mary E. Martin, Lucie C. Lepine, Marie-Louise Smith, Thomas D. Lee, Ralph O. Dubayah, Michelle A. Hofton, Peter Hyde, Birgit E. Peterson, and J. Bryan Blair 


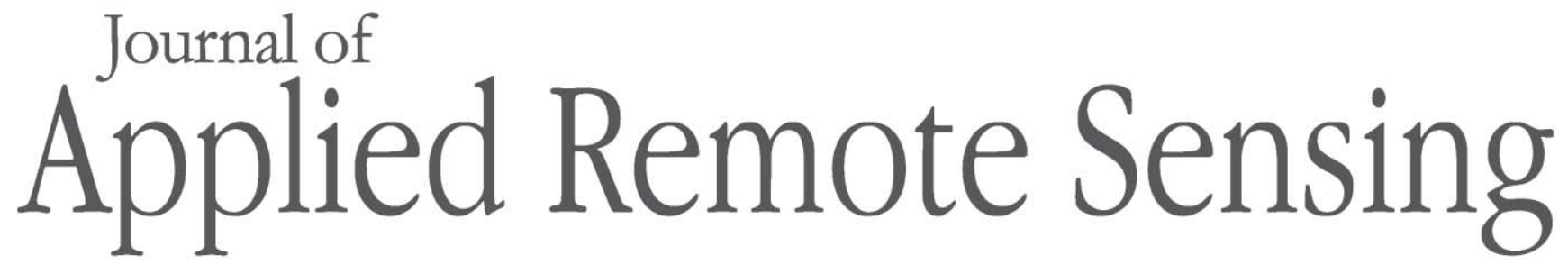

Use of waveform lidar and hyperspectral sensors to assess selected spatial and structural patterns associated with recent and repeat disturbance and the abundance of sugar maple (Acer saccharum Marsh.) in a temperate mixed hardwood and conifer forest

Jeanne E. Anderson et al. 


\title{
Use of waveform lidar and hyperspectral sensors to assess selected spatial and structural patterns associated with recent and repeat disturbance and the abundance of sugar maple (Acer saccharum Marsh.) in a temperate mixed hardwood and conifer forest
}

\author{
Jeanne E. Anderson, ${ }^{\text {a }}$ Mark J. Ducey, ${ }^{\mathrm{b}}$ Andrew Fast, ${ }^{\mathrm{c}}$ Mary E. Martin, ${ }^{\mathrm{a}}$ \\ Lucie Lepine, ${ }^{a}$ Marie-Louise Smith, ${ }^{d}$ Thomas D. Lee, ${ }^{b}$ Ralph O. Dubayah, \\ Michelle A. Hofton, ${ }^{\mathrm{e}}$ Peter Hyde, ${ }^{\mathrm{e}}$ Birgit E. Peterson, ${ }^{\mathrm{f}}$ and J. Bryan Blair ${ }^{\mathrm{g}}$ \\ ${ }^{a}$ University of New Hampshire, Complex Systems Research Center, Institute for the Study of \\ Earth, Oceans, and Space, Durham, New Hampshire 03824-3589 \\ jeanne.anderson@alumni.unh.edu; mary.martin@unh.edu; lucie.lepine@unh.edu \\ ${ }^{\mathrm{b}}$ University of New Hampshire, Department of Natural Resources and the Environment, \\ Durham, New Hampshire 03824-3589 \\ mark.ducey@unh.edu; tom.lee@unh.edu \\ ${ }^{\mathrm{c}}$ University of New Hampshire, Cooperative Extension, Durham, New Hampshire 03824-3589 \\ afast@ceunh.unh.edu \\ ${ }^{\mathrm{d}}$ U.S.D.A. Forest Service, Washington, D.C. 20250 \\ marielouisesmith@fs.fed.us \\ ${ }^{\mathrm{e}}$ University of Maryland, Department of Geography, College Park, Maryland 20742 \\ dubayah@umd.edu; mhofton@umd.edu \\ ${ }^{\mathrm{f}}$ USGS Center for Earth Resources Observation and Science, Sioux Falls, South Dakota 57198 \\ bpeterson@usgs.gov \\ ${ }^{\mathrm{g}}$ Goddard Space Flight Center, NASA, Laser Remote Sensing Branch, Greenbelt, Maryland, \\ 20771 \\ james.b.blair@nasa.gov
}

\begin{abstract}
Waveform lidar imagery was acquired on September 26, 1999 over the Bartlett Experimental Forest (BEF) in New Hampshire (USA) using NASA's Laser Vegetation Imaging Sensor (LVIS). This flight occurred 20 months after an ice storm damaged millions of hectares of forestland in northeastern North America. Lidar measurements of the amplitude and intensity of ground energy returns appeared to readily detect areas of moderate to severe ice storm damage associated with the worst damage. Southern through eastern aspects on side slopes were particularly susceptible to higher levels of damage, in large part overlapping tracts of forest that had suffered the highest levels of wind damage from the 1938 hurricane and containing the highest levels of sugar maple basal area and biomass. The levels of sugar maple abundance were determined through analysis of the 1997 Airborne Visible/Infrared Imaging Spectrometer (AVIRIS) high resolution spectral imagery and inventory of USFS Northern Research Station field plots. We found a relationship between field measurements of stem volume losses and the LVIS metric of mean canopy height $\left(r^{2}=0.66\right.$; root mean square errors $=5.7 \mathrm{~m}^{3} / \mathrm{ha}, \mathrm{p}<$ 0.0001) in areas that had been subjected to moderate-to-severe ice storm damage, accurately documenting the short-term outcome of a single disturbance event. ๑ 2011 Society of Photo-Optical Instrumentation Engineers (SPIE). [DOI: 10.1117/1.3554639]
\end{abstract}

Keywords: lidar, hyperspectral; ice storm; tree mortality; stem volume losses; Acer saccharum.

Paper 10030R received Mar. 5, 2010; revised manuscript received Jan. 7, 2011; accepted for publication Jan. 21, 2011; published online Mar. 11, 2011.

$1931-3195 / 2011 / \$ 25.00$ @ 2011 SPIE 


\section{Introduction}

In regions prone to catastrophic wind events, it has been suggested by Foster et al. ${ }^{1}$ that persistent landscape-scale variation in site susceptibility can strongly influence patterns of forest damage and may, as a consequence of the frequency and intensity of disturbance, also control such ecological characteristics as canopy structure, the spatial pattern and traits of successional and old-growth forests, and primary production. It has also been increasingly recognized that in addition to major wind events, ice storm damage is a significant factor in the structuring of forests; under certain conditions, reaching levels of biomass and basal area damage that rival or even exceed the magnitude of damage seen with major hurricanes. ${ }^{2}$ Factors controlling the pattern of forest damage from such disturbances include gradients of wind velocity, topographic exposure, site condition, composition, structure, and history. ${ }^{3}$

For parts of northern New England, two of the most significant, wide-ranging natural disturbances of the past century were the September 1938 hurricane and the January 1998 ice storm. These storms occurred 60 years apart and impacted some of the same landscape, particularly in north-central New Hampshire. Information on the characteristic distribution and legacies of these natural disturbances over time and space has been reported and simulated in the northeast from a few well-studied sites, ${ }^{4-10}$ but the demand for agencies charged with forest management to remotely and repeatedly document the spatial extent and magnitude of such events on a broader scale has been increasing over time. ${ }^{11,12}$ Knowledge of the variability found within these patterns is also important to efforts to accurately model carbon balances worldwide.

Waveform-recording lidar (hereinafter lidar) can readily detect the spatial patterns of large, infrequent disturbance. ${ }^{13,14}$ As a remote sensing tool with excellent ability to characterize various aspects of forest structure and light patterning, as well as elevation, ${ }^{15,16}$ it can be used to reveal environmental controls on patterns that are specific to particular types of disturbances. Relationships between lidar metrics and tree mortality found in forested areas subjected to recent disturbance have not been extensively studied. But such findings, especially when combined with compositional data revealed through spectral imagery, could increase the possibilities to remotely map and quantify the overall impacts resultant from site susceptibility to repeated natural disturbance events.

In New England, severe damage from the 1938 hurricane has been characteristically, but not exclusively, reported on south-to-east facing slopes. ${ }^{17-19}$ Similarly, Lafon et al. ${ }^{20}$ described ice storm impacts from two successive storms in Virginia where the heaviest forest damage occurred on mountain slopes facing south and east, while Millward and Kraft ${ }^{21}$ reported that damage from the January 1998 ice storm in the Adirondacks was concentrated at locations with a landscape orientation facing eastward and ranging between northwest and southeast. They also reported impacts concentrated at elevations ranging from 200 to 600 m. Rhoads et al. ${ }^{22}$ have documented the effect of the January 1998 ice storm on the northern hardwood canopy at Hubbard Brook. They reported that damage in the 60 to 120 year old south-facing watersheds was greatest in trees $>30-\mathrm{cm}$ diameter at breast height and at elevations above $600 \mathrm{~m}$. Of the dominant tree species within that northern hardwood forest, beech was the most damaged, sugar maple was the most resistant, and yellow birch was intermediate.

It has been noted ${ }^{23}$ that periodic storms of intermediate severity allow interspecific differences in canopy tree survival to play a strong role in succession, with forests becoming progressively wind-firm and less susceptible to wind disturbance in the absence of catastrophic events. Their findings in mature northern hardwood forests report that yellow birch and sugar maple have the lowest levels of windthrow; accounting in part for their relatively high abundance in old-growth forests. ${ }^{24}$ While the return intervals for extreme catastrophic disturbance of northern temperate forests may be measured over centuries, historical records also suggest that storms with winds or ice sufficient to damage a significant fraction of canopy trees in a stand occur at frequencies measured in decades to scores of years. ${ }^{25}$ 
Further data on the return time between such moderate-to-severe natural disturbances and comparable links between disturbance frequency and compositional status of northeastern hemlock-northern hardwoods forests is provided in Ref. 26. Disturbance intensity was directly related to site elevation and exposure, decreasing from the upland to riparian sites. Upland sites (stand age approximately 350 years) experienced medium-intensity disturbances $(>20 \%$ canopy damage) nearly every 30 years with four decades exhibiting severe disturbances ( $>40 \%$ canopy damage), resulting in higher importance of early successional taxa on uplands. The side slope site (stand age 350 years) experienced medium-intensity disturbances every decade with only one severe intensity disturbance. The riparian site (stand age 250 years) was impacted by medium-intensity disturbances every 80 years with no severe disturbances in the last 250 years, resulting in the dominance of these sites by later successional hemlock and beech. Recruitment patterns were affected by disturbance intensity, with successional hardwood species such as yellow birch and red maple recruiting only after medium-to-heavy intensity disturbances, and later successional hemlock and beech recruiting successfully with low-intensity disturbances.

Significant canopy damage was inflicted on the Bartlett Experimental Forest (BEF) in northcentral New Hampshire by both the 1938 hurricane and the 1998 ice storm (Forest Service records, M. L. Smith, personal communication). Airborne remote sensors collecting both spectral and physical attribute data were flown over Bartlett relatively close to the time frame of the 1998 storm. The close juxtaposition of the heaviest damage from both storm events over the same tracts of northern temperate mixed deciduous forest at Bartlett provides an opportunity to use these remote sensing data to look for emergent structural properties that may result from repeat exposure to storms of intermediate severity. The intent of this paper is to assess the use of waveform lidar and hyperspectral sensor data to locate the spatial and structural patterns that emerge as the legacies of repeat disturbances at this specific site within the White Mountain National Forest.

\section{Methods}

\subsection{Site}

Over the past 70 years, the USFS northern research station (NRS) has assembled a large volume of field data (e.g., Refs. 27-32) on a variety of ecosystem processes and forest metrics within the 1052-hectare BEF located within the White Mountain National Forest in the central White Mountains (Fig. 1). The landscape of this site reflects an extensive history of experimental forest management and varied natural disturbance regimes. Deciduous and coniferous forest types including northern hardwood \{e.g., sugar maple [Acer saccharum Marsh.], beech [Fagus grandifolia Ehrh.], yellow birch [Betula alleghaniensis Britton], red spruce-balsam fir [Picea rubens Sarg.-Abies balsamea (L.) Miller], eastern hemlock [Tsuga canadensis (L.) Carr.], and red oak-white pine [Quercus rubra L - Pinus strobus L.] ] are represented on a site ranging in elevation from 200 to $850 \mathrm{~m}$. Slopes vary from flat terrain to nearly vertical (rock cliff) conditions. The forest reflects a range of successional sequences, forest patch sizes, and structural distributions. Clear-cutting, group and individual tree selection, basal area and shelter-wood cuttings have been undertaken on approximately $55 \%$ of the forest. Forest ages in managed stands range from more than 70 to less than 5 years old. Half of the forest serves as an unmanaged, natural control, characterized by natural forest disturbance regimes, with ages ranging upward of 100 years. $^{33}$

\subsection{Aspect}

For this study, aspect (Fig. 2) was determined using a digital elevation model derived from the bilinear interpolation of a USGS national elevation data set. ${ }^{34}$ Eight classes, each encompassing a range of $45^{\circ}$ plus an additional class for flat terrain were established using tools within the 


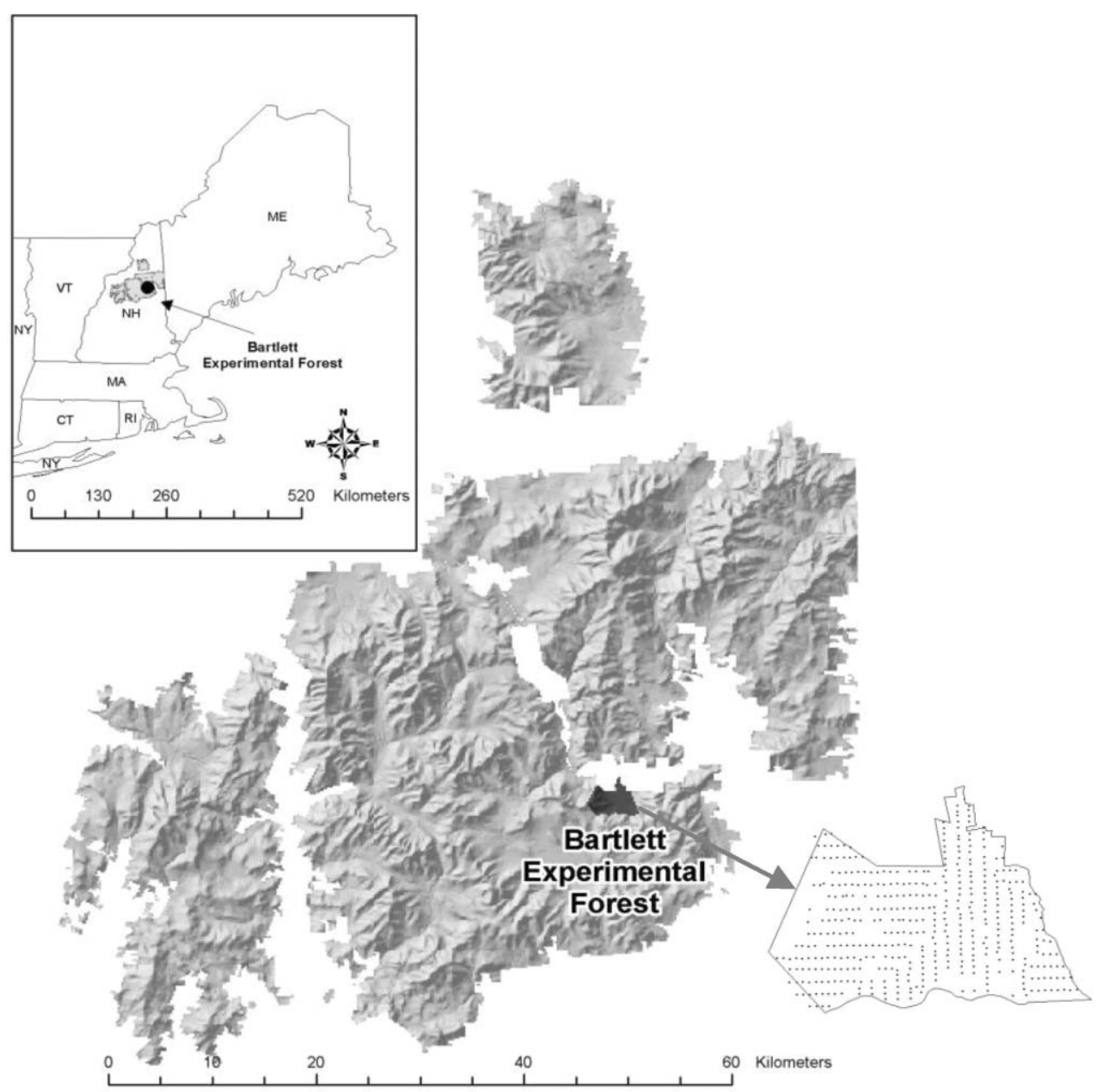

Fig. 1 Location of Bartlett Experimental Forest, showing established plot network.

spatial analyst extension of ArcGIS (v. 8.3) (ESRI 1999 to 2002). Eastern through southern aspects specifically range from 67.5 to $202.5^{\circ}$.

\subsection{USFS NRS Inventory Plots}

The USFS NRS originally established a regular grid of approximately 500 permanent research plots at Bartlett Experimental Forest in 1931 to 1932 (Fig. 1). Re-sampling of over 400 of these 0.1 ha square plots was undertaken by the USFS NRS in the 2001 to 2003 field seasons. Based on the historical sampling protocols established in the 1930s, measurements tally species and dbh in 1-in. $(2.54 \mathrm{~cm})$ dbh classes for trees greater than 1.5 in. $(\mathrm{ca} .4 \mathrm{~cm})$ in size. Basal area and dry weight biomass (AGBM: bole, branch, and foliar) by species for each inventory plot was calculated using regionally developed allometric equations based on stem diameter measurements. ${ }^{35}$ Fraction of biomass by species per plot was calculated from the most recent BEF survey data. All inventory plots have been geo-referenced to within 3-m positional accuracy. These data provide a comprehensive ground inventory of standing biomass and species composition of the BEF.

\subsection{Lidar Data}

Lidar data was acquired on September 26, 1999 over the BEF using NASA's laser vegetation imaging sensor (LVIS). ${ }^{36}$ Nine flight lines were completed between Bartlett and West Thornton, 


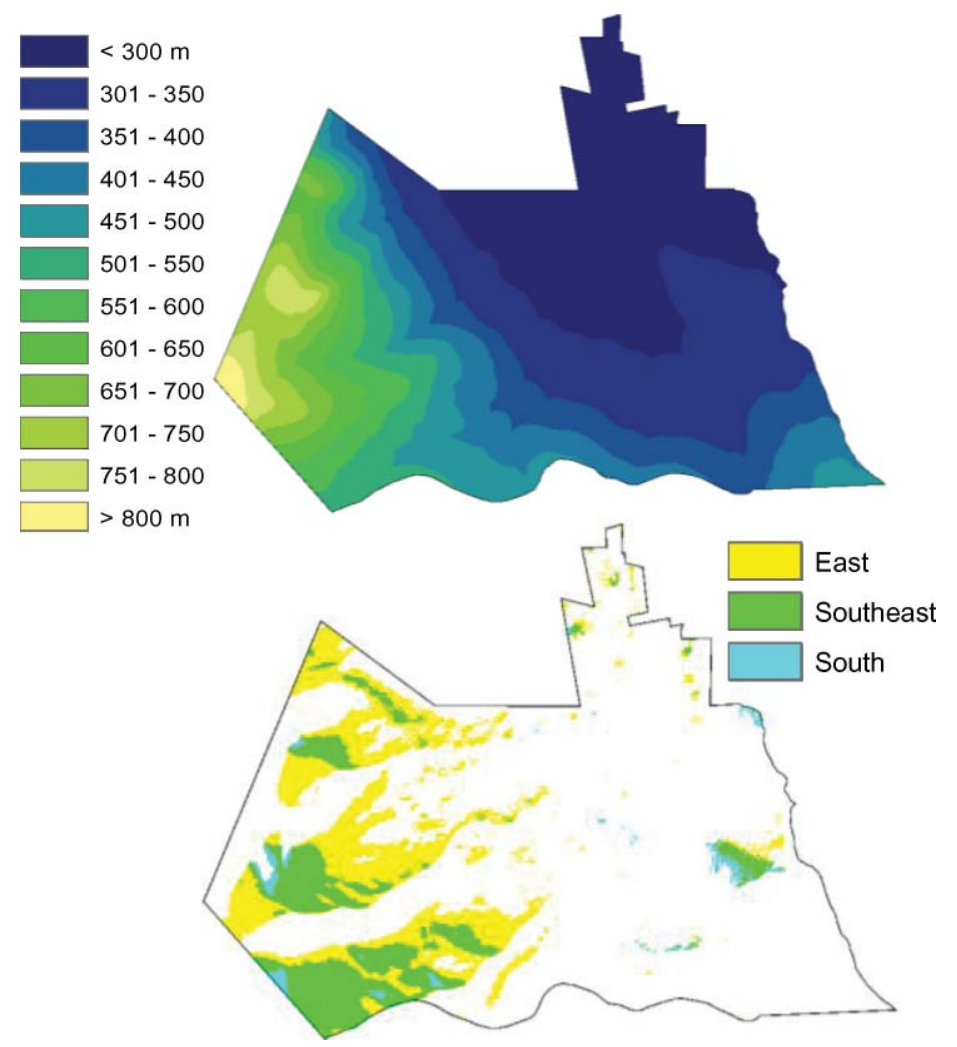

Fig. 2 Bartlett Experimental Forest. Selected aspects and elevations.

New Hampshire LVIS is an airborne imaging laser altimeter that records the time and amplitude of a laser pulse reflected off target surfaces. The sensor digitizes the vertical distribution of intercepted surfaces between the first (top of the canopy) and the last (ground) return producing a waveform record. LVIS records circular footprints of variable size; 1999 footprints had a nominal radius of $12.5 \mathrm{~m}$. 52,279 footprints falling within the boundaries of BEF were available for this analysis. Additional detail on LVIS capabilities can be found in Blair et al. ${ }^{37}$

LVIS metrics used in this study were derived from the waveforms using an automated algorithm. ${ }^{38,39}$ Lidar canopy height (LHT) was calculated by identifying two locations within the waveform where: 1 . the signal initially increases above a mean noise level/threshold (the canopy top) and 2. at the center of the last Gaussian pulse (the ground return). The distance between these two locations was then calculated to derive the height metric (Fig. 3) The height of median energy (HOME) was calculated by finding the median of the entire signal (i.e., above the mean noise level) from the waveform, including energy returned from both canopy and ground surfaces. The location of the median energy was then referenced to the center of the last Gaussian pulse to derive a height. ${ }^{40}$ The ground return energy metric (GRND) was determined by taking the total intensity (i.e., number of digitizer counts) contained in all approximately $30-\mathrm{cm}$ vertical bins contained in the last Gaussian peak; ${ }^{41}$ (Fig. 3). Canopy energy (CAN_E) is calculated as the total intensity of the entire waveform minus GRND.

\subsection{Tree Mortality}

Line-intercept sampling ${ }^{42-44}$ was utilized to estimate tree mortality on 190 transects within the Bartlett Experimental Forest in 2004. Each transect was approximately $100 \mathrm{~m}$ in length originating at the primary corner of a USFS NRS permanent inventory plot. All fallen trees 


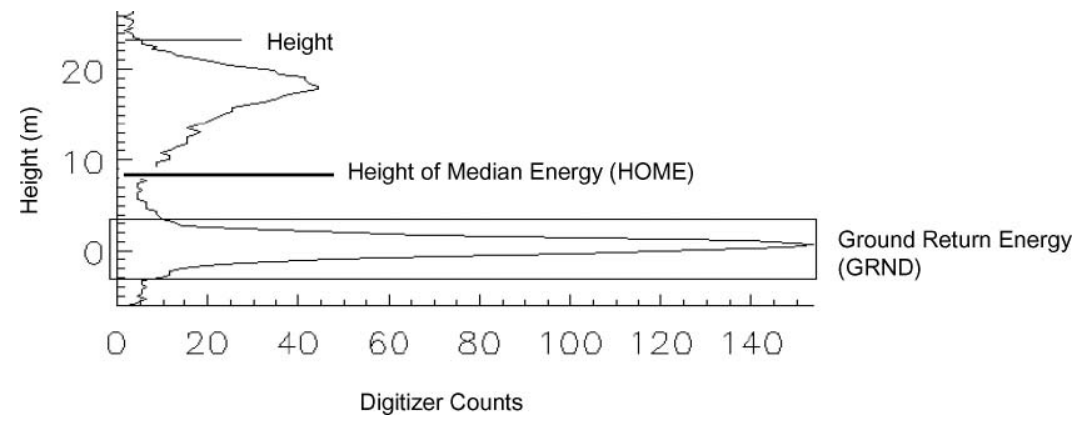

Fig. 3 Metrics derived from lidar waveforms. Adapted from Ref. 40.

or parts of trees with a diameter greater than $7.62 \mathrm{~cm}$ ("logs") were recorded. Measurements included $\log$ length, end of log diameters, and orientation of fall. Logs were identified to species or hardwood/softwood categories where possible and the approximate cause of mortality was identified.

Logs were assigned to one of eight decay classes. Decay classes were established based on refinement of the five-class system of Pyle and Brown ${ }^{45,46}$ and are detailed in Fast et al. ${ }^{47}$ The range in years since mortality encompassed within any given decay class of fallen logs was classified based on analysis of an ongoing silvicultural study established at BEF in 1963 and $1964 .{ }^{48-50}$ All trees within forty-eight 0.135 ha plots were identified, tagged, and mapped; plots were inventoried every 2 to 6 years: 1967, 1969, 1972, 1974, 1980, 1985, 1989, 1991, 1995, 2000, and 2004. This data allowed a range of time each log has been on the ground to be determined. Logs were assigned to decay classes in 2004 and cross-tabulated with time since mortality. The cumulative percentage of logs of a given age within any decay class was subsequently calculated..$^{51}$ For example, decay classes I and II encompass hardwood logs that have been on the ground for anywhere from 1 to 13 years, with $89 \%$ of the logs in decay class I having been on the ground for six years or less and $44 \%$ of the logs from decay class II having been on the ground for six years or less.

For this study, estimates of volume per hectare were adjusted using decay-class specific multipliers to estimate the volume that had fallen within the six-year time frame since the occurrence of the 1998 ice storm. Volumes associated with individual fallen logs were estimated using Honer's equations. ${ }^{52}$ These volumes reflect whole-tree stemwood volume, not necessarily the volume of the individual pieces tallied. Thus, the volume estimates reflect stem volume losses due to mortality, not necessarily the volume of wood actually present on the forest floor. Downed wood on the forest floor would be expected to be slightly less due to decay and breakage. Because transects were not oriented randomly, and the assumption that logs are oriented randomly is generally untenable, we used the direction of fall information in conjunction with transect orientation to scale individual log volumes to per-hectare estimates using Kaiser's conditional estimator. ${ }^{53}$

\subsection{AVIRIS}

Sugar maple abundance classification was derived from high spectral resolution imagery (Fig. 4). Image data were acquired using NASA's airborne visible/infrared imaging spectrometer (AVIRIS). AVIRIS records data in 224 contiguous spectral bands covering the spectral range of 0.4 to $2.4 \mu \mathrm{m}$ with a spectral resolution of $0.01 \mu \mathrm{m}$. The spatial resolution of AVIRIS data is $20 \mathrm{~m}$ with a full scene covering $11 \times 10 \mathrm{~km} \cdot{ }^{54}$ Cloud-free AVIRIS imagery was obtained for the entire White Mountain National Forest in New Hampshire in August 1997. A subset of this image data set was created to include only BEF. This image was then atmospherically corrected using ATREM 3.1 (Ref. 55) and geometrically corrected with ERDAS Imagine v. 8.5. 


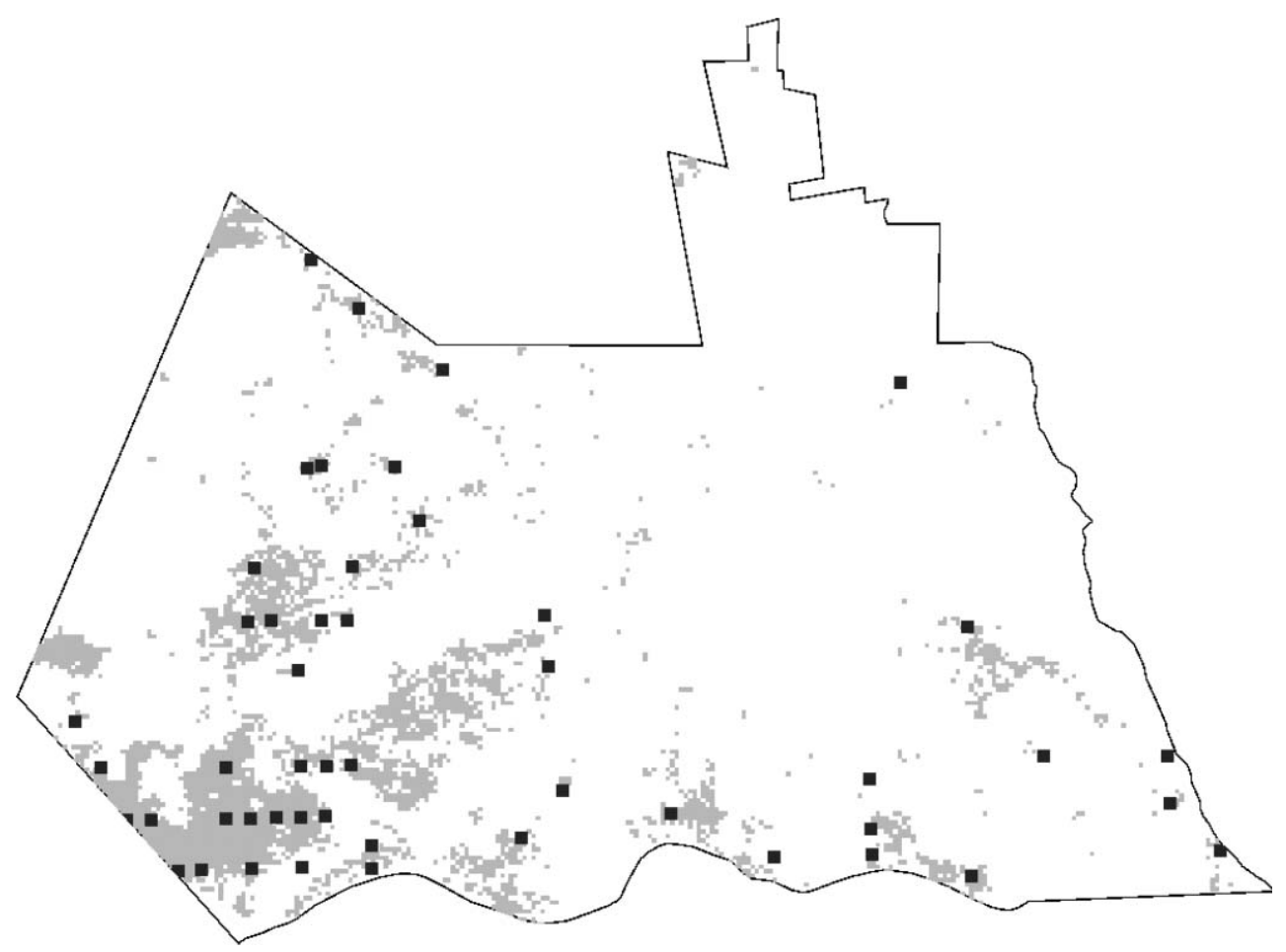

Fig. 4 Sugar maple basal area $>30 \%$ (gray shading) derived from 1997 AVIRIS imagery and fraction of sugar maple biomass $>0.3$ (dark black squares) derived from 2001 to 2003 USFS NRS inventory.

Wavelength channels were evaluated in the AVIRIS image using the ENVI (v. 3.6) animation tool, and those with strong water absorption features and low signal-to-noise were excluded from further analysis. The AVIRIS image was then transformed with a minimum noise fraction transform ${ }^{56,57}$ to reduce data dimensionality in preparation for spectral unmixing. Spectral unmixing methodology was chosen to determine sugar maple abundance because it allows for delineating sub-pixel composition, and is therefore particularly useful in the predominantly mixed stands of BEF (see Refs. 58-61).

Inventory data collected for more than 400 plots in BEF in the early 1990s provided the basis for estimates of sugar maple abundance. Regions of interest (ROIs) were created in the AVIRIS image using relative sugar maple abundance calculated from the basal area for 163 of the plots. Following Ref. 62, the endmembers from these ROIs were applied to a matched filtering algorithm in ENVI ${ }^{63,64}$ to map six classes of sugar maple abundance: 1 to $10 \% ; 11$ to $20 \% ; 21$ to $30 \%$; 31 to $40 \% ; 41$ to $50 \%$; and greater than $50 \%$. Resulting estimates of sugar maple abundance fell within one $10 \%$-class of basal area measurements $77 \%$ of the time.

Maps were analyzed using ENVI v. 4.2, Imagine v. 8.7, and ArcGIS v. 8.3 software.

\section{Data Analysis}

\subsection{Canopy Closure and LVIS Metrics}

Assessment of the openness of the canopy was approached by looking at LVIS metrics in two separate ways (the direct measure of GRND versus a normalized ratio of canopy closure). At Bartlett, high values of ground energy reflect an open canopy. This was compared for its correspondence with an indirect measure of canopy closure calculated by using two of the LVIS variables (i.e., canopy energy and ground energy) in order to present a measure of canopy closure 
that utilized a normalized and more recognizable metric (i.e., a percentage value) of openness. Canopy closure was estimated using 1999 LVIS metrics of CAN_E and GRND.

"The percentage of canopy closure was calculated as:

$$
\text { CAN_E/(CAN_E + 1.6 GRND) }{ }^{*} 100 \text {, }
$$

where CAN_E = LVIS canopy energy, GRND = LVIS ground energy, and 1.6 is a correction factor derived from the ratio of canopy to ground reflectance." ${ }^{" 65}$

\subsection{Sugar Maple Abundance and LVIS Metrics}

USFS NRS inventory plot data for the BEF was used to examine relationships between sugar maple abundance, aspect, and 1999 LVIS measures of ground return energy. In comparison to the 0.1 ha square USFS NRS inventory plots, the 1999 LVIS circular footprints are 0.049 hectares in size. Given the variable overlap of LVIS flight lines during the 1999 flight over Bartlett, any given USFS NRS plot contained the center points of from 1 to 10 lidar footprints. For each of these plots, mean values were calculated for the 1999 LVIS metrics (e.g., elevation and GRND) derived from footprints with center points located within the bounds of USFS NRS plots. Analysis was restricted to 145 plots where sugar maple was present at elevations above $325 \mathrm{~m}$ with mean tree height exceeding $19 \mathrm{~m}$. Plots were then aggregated by aspect and mean values of sugar maple abundance and mean ground energy generated for each group.

\subsection{Tree Mortality and LVIS Metrics}

As described above, the fallen tree volume data for Bartlett was adjusted to estimate the fraction of volume derived from logs that had fallen within six years. This six year period corresponds to the time frame between mortality data collection and the last major natural disturbance within this forest; the ice storm of January 1998. A $20 \mathrm{~m} \times 100 \mathrm{~m}$ polygon (hereinafter called the mortality plot) originating from the NRS primary plot corner was used to encompass each mortality transect and to define an area from which the center points of the 1999 LVIS footprints that fall within the plot could be extracted.

Given the variable overlap of LVIS flight lines during the 1999 flight over Bartlett, any given mortality plot contained the center points from between 1 to 18 lidar footprints. For each of the 190 mortality transects, mean values and their squares were calculated for the LVIS 1999 metrics (LHT, HOME, GRND, CAN_E) derived from footprints with center points located within the bounds of the mortality plots.

To find relationships specific to those areas of Bartlett that contain mature, northern hardwood forest with open or damaged canopy, three restrictions were imposed on the dataset. Sites were chosen where: 1 . the LVIS measure of the intensity of ground return energy was relatively high (mean GRND > 2250; this digitizer count value is equivalent to the highest $17 \%$ of ground return values in the dataset), 2. mean elevation exceeded $325 \mathrm{~m}$ and 3. LVIS canopy height reflected the height of the mid-successional forest (mean height $>19 \mathrm{~m}$; Fig. 5). The latter restrictions removed from considering those sites at Bartlett that have been subject to recent forest management and gave emphasis to sloped forest tracts comprised largely of northern hardwood species. Eighteen mortality plots met these restrictions (Fig. 5).

The relationships between the mortality estimates and the mean values of four LVIS variables (LHT, HOME, GRND, and CAN_E) were explored through stepwise mixed linear regression techniques. Statistical analyses were conducted using JMP IN software (SAS Institute, Inc., 2005). Dependent variables (mortality estimates), independent variables (LVIS metrics), and the regression residuals were tested for normality of their distributions using the Shapiro-Wilk $\mathrm{W}$ test ${ }^{66}$ and normal quantile plots. Prediction error sum of squares root mean square errors (PRESS RMSE) were calculated for each forest metric. PRESS RMSE is computed as the square 


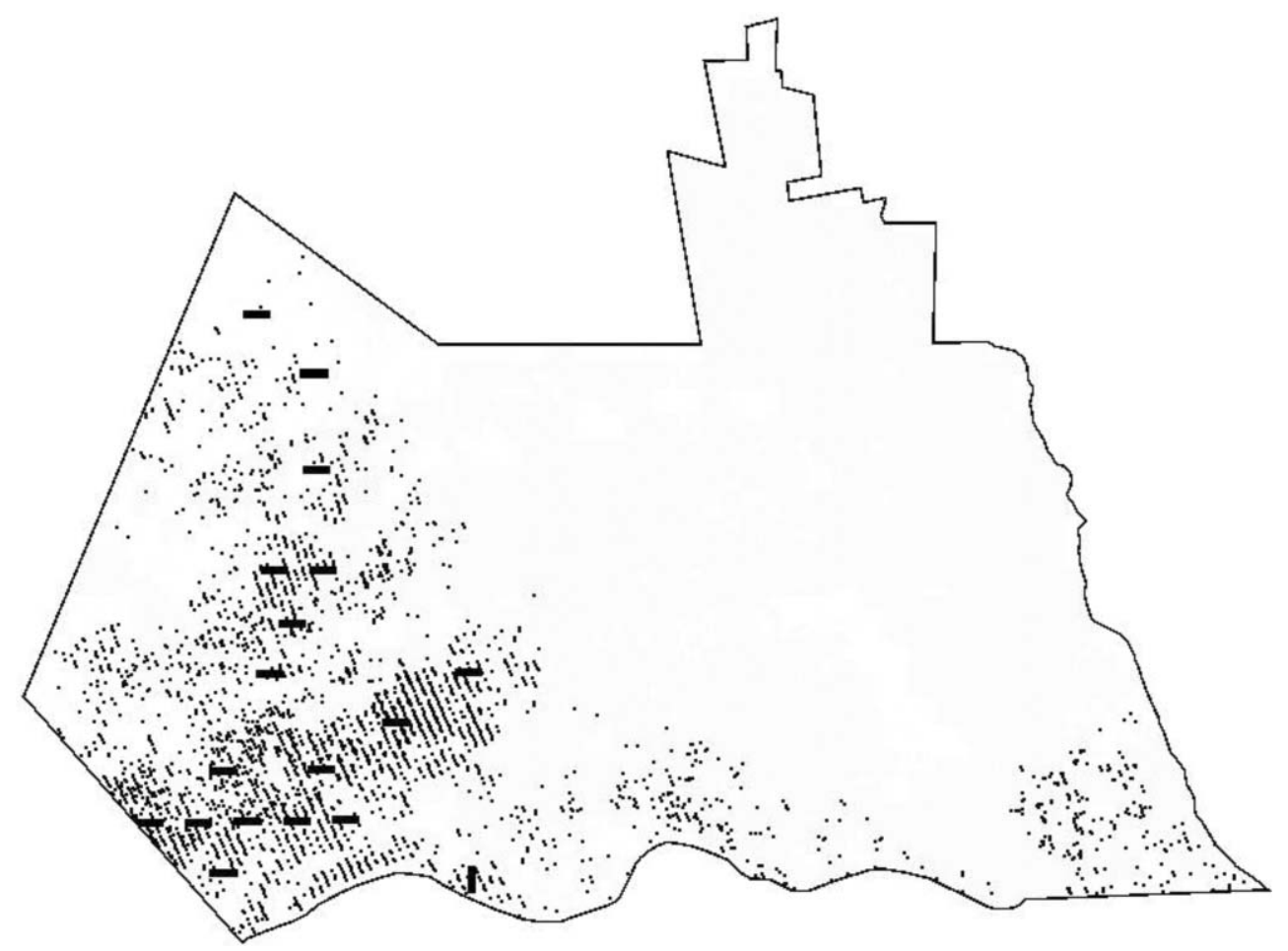

Fig. 5 Locations of 18 mortality transects (black polygons). Transects were selected by restricting analyses to only those sites where the aggregated 1999 LVIS ground energy metrics (gray points) were relatively high (the upper $17 \%$ of mean ground energy values), LVIS mean elevation was greater than $325 \mathrm{~m}$ and LVIS minimum canopy height was above $19 \mathrm{~m}(62 \mathrm{ft})$ for the forest as a whole. These restrictions selected for those areas of Bartlett that contain predominately mature northern hardwood forest with open or damaged canopy, thus allowing LVIS photons to reach the ground at higher levels. Transects selected are all located within the area of Bartlett that suffered the greatest damage from the January 1998 ice storm.

root sum of squares of the prediction residuals. ${ }^{67,68}$ As an out-of sample validation technique, PRESS RMSE tests how well the current model would predict each of the points in the data set (in turn) if they were not included in the regression. Low values of PRESS RMSE usually indicate that the model is not overly sensitive to any single data point.

\section{Results}

\subsection{Canopy Closure and LVIS Metrics}

Correspondence between footprints with less than $65 \%$ canopy closure with the highest $10 \%$ values of 1999 LVIS ground energy metrics can be seen in Fig. 6. BEF is a nearly complete forested landscape. Openness in this forest is either the direct result of recent clear or partial cutting since the mid-1990s (see management tracts demarcated at lower elevations in Fig. 6) or reflects a history of natural disturbance. Apart from areas of active forest management, remaining low canopy closure and/or high LVIS ground energy return values are most evident within the tracts of forest subjected to the greatest amount of 1998 ice storm damage. This spatial patterning provides additional context for the use of the GRND (as a variable that can indicate the overall openness of canopy conditions in forest analyses) in the quantitative examination of the relationships between high levels of ground return energy metrics, abundance of sugar maple, and aspect explored and presented in Fig. 8. 


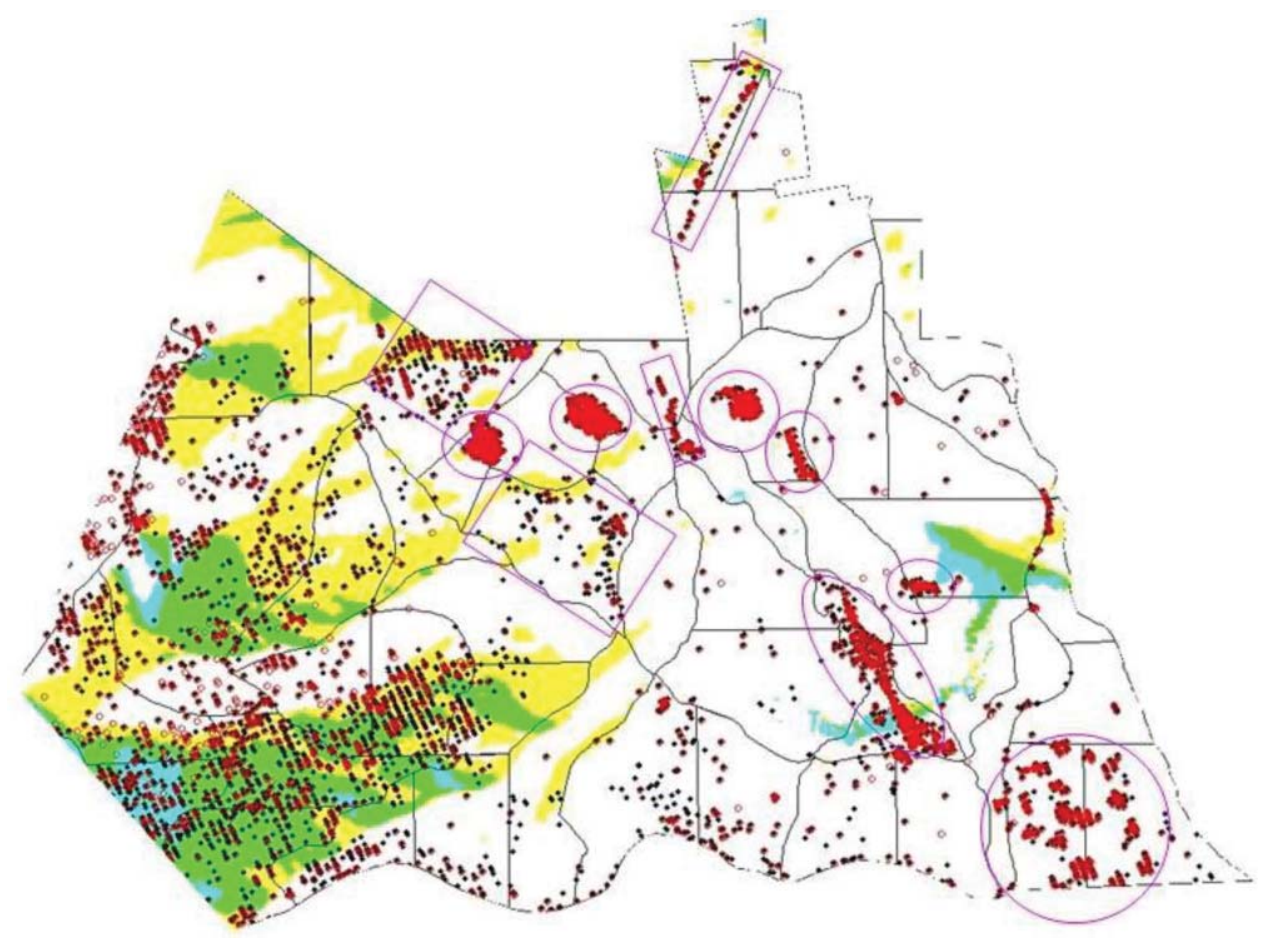

Fig. 6 Comparison of 1999 LVIS-derived minimal canopy closure versus high levels of LVIS ground return energy metric. See online version to view in color. Canopy closure is calculated as $\mathrm{CC}=\mathrm{CAN}$ _E/(CAN_E $\left.+1.6{ }^{*} \mathrm{GRND}\right)$; $\mathrm{CC}<65 \%$; red circles. Upper $10 \%$ of GRND values: black footprints. Selected aspects are shown by shading: $\mathrm{S}=$ blue; $\mathrm{SE}=$ green; $\mathrm{E}=$ yellow. Areas demarcated by polygons and ovals in purple have been subjected to recent active forest management (clear or partial cutting since the mid-1990s).

\subsection{Sugar Maple Abundance and LVIS Metrics}

A strong association between areas supporting a greater than $30 \%$ basal area of sugar maple with the higher values of 1999 LVIS ground energy metrics is visually apparent in Fig. 7 . The overlap is particularly striking on forest tracts with southern through eastern aspects. USFS NRS field data (Fig. 8) also indicates that plots located on southeastern aspects at Bartlett support a higher abundance of sugar maple and higher levels of measured ground return energy. Analysis of variance of 1999 LVIS mean ground energy metrics versus aspect was significant $(p<0.001)$ for all 411 plots sampled by the forest service, as well as for the smaller subsets of 277 plots where sugar maple was present and 145 plots restricted to mature forests above elevations of $325 \mathrm{~m}$. The distribution of sugar maple abundance was non-normal and Kruskal-Wallis analysis of sugar maple abundance versus aspect was significant at $p<0.007(N=145)$ and $p<0.001$ $(N=277$ and 411). Sugar maple mortality from decay classes I and II is virtually non-existent within these same areas with only $8 \operatorname{logs}$ out of $437(2 \%) \operatorname{logs}$ found within those two decay classes in the forest as a whole (Fig. 7). Sugar maple mortality from decay classes I to III accounted for only $4 \%$ of the downed logs within the forest.

\subsection{Mortality and LVIS Metrics}

The restrictions in elevation, canopy height, and LVIS GRND intensity, described above, resulted in the selection of 18 mortality plots in the western half of Bartlett. Of these, 17 are largely hardwood sites, with beech predominant among the fallen trees. Sixteen of these 18 plots are located on southern, southeastern, or eastern aspects (Fig. 7). All transects were located 


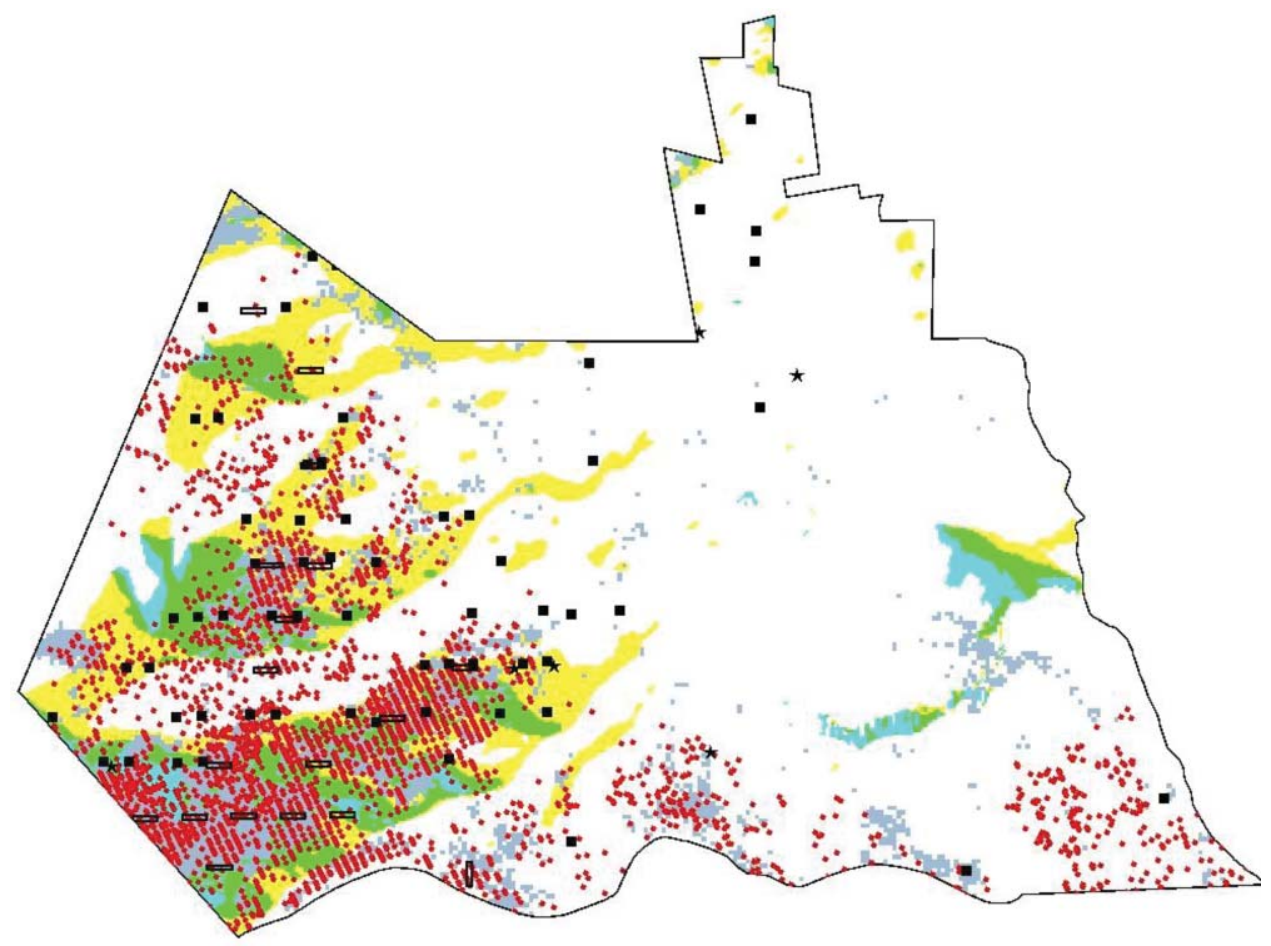

Fig. 7 Comparison of high levels of sugar maple abundance, LVIS ground return energy, and 1938 hurricane damage with reference to aspect, and selected mortality data. See online version to view in color. Sugar maple abundance basal area $>30 \%$ : slate blue shading. Upper $17 \%$ of GRND in mature forest (LHT > $19 \mathrm{~m}$ and elevations $>325 \mathrm{~m}$ ): red circular footprints. Selected aspects are shown by shading: $\mathrm{S}=$ light blue; $\mathrm{SE}=$ green; $\mathrm{E}=$ yellow. USFS NRS plots with basal area damage $>20 \%$ from 1938 hurricane: solid squares. Selected mortality transects: open rectangles. Sugar maple fallen trees from decay classes I and II shown with stars (8 logs of $467 ; 2 \%)$.
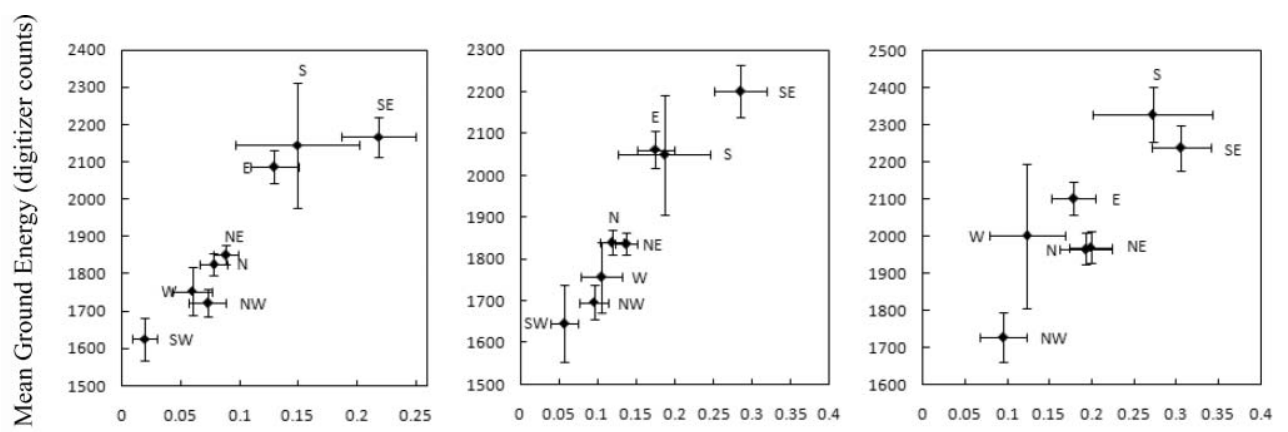

Sugar Maple: Mean Fraction of Basal Area

$\mathrm{N}=411$

$$
\mathrm{N}=277
$$

$\mathrm{N}=145$

Fig. 8 USFS NRS inventory plot data for the Bartlett Experimental Forest were used to examine relationships between sugar maple abundance, aspect, and 1999 LVIS measures of ground return energy. Analysis examined all sampled plots $(N=411)$, the subset of plots where sugar maple was present $(N=277)$, and the subset of plots where sugar maple was present at elevations above $325 \mathrm{~m}$ and mean tree height exceeded $19 \mathrm{~m}(N=145)$. Plots were aggregated by aspect with mean values of sugar maple abundance and mean ground energy generated for each group. Standard error of variables is shown. 


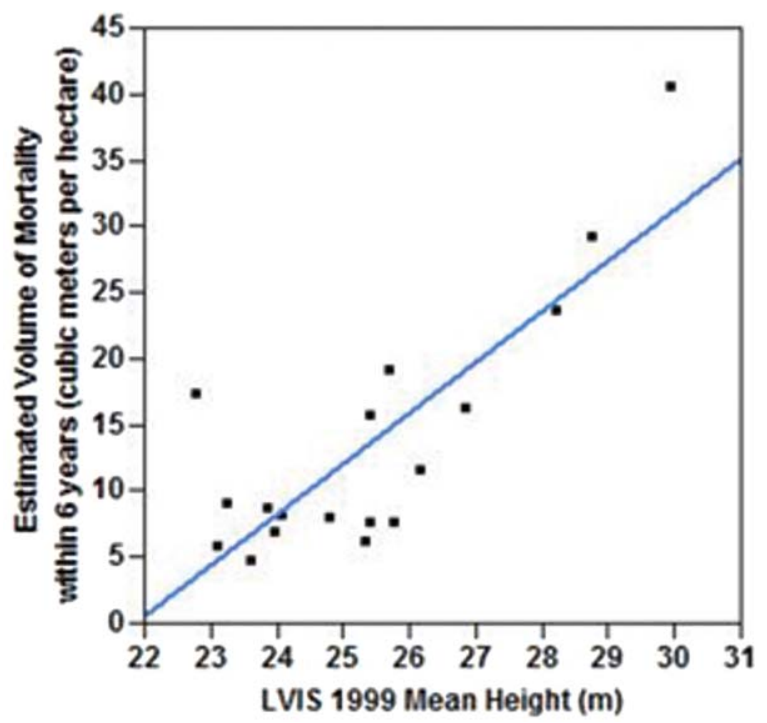

Fig. 9 Scatter plot of estimated volume of mortality within six years with the mean canopy height of aggregated 1999 LVIS metrics. Simple linear regression generated the following results: $r^{2}=0.66$, RMSE $5.7 \mathrm{~m}^{3} /$ ha, PRESS RMSE $6.5 \mathrm{~m}^{3} / \mathrm{ha}, \mathrm{N}=18, \mathrm{p}<0.0001$. Mortality transects were restricted by choosing only sites where the LVIS ground energy metrics were relatively high (i.e., the upper $17 \%$ of mean ground energy values), mean elevation exceeded $325 \mathrm{~m}$, and LVIS minimum canopy height was greater than $19 \mathrm{~m}$ for the forest as a whole.

within the area of Bartlett that suffered the heaviest amounts of damage from the 1998 ice storm. Under these restrictions, the relationship between the estimated volume of mortality within six years with the mean canopy height of aggregated 1999 LVIS height metrics is shown below $\left(r^{2}=0.66\right.$; RMSE $=5.7 \mathrm{~m}^{3} /$ ha, PRESS RMSE $6.5 \mathrm{~m}^{3} / \mathrm{ha}, p<0.0001 ;$ Fig. 9).

\section{Discussion}

The premise described by Foster et al. ${ }^{69}$ of persistent landscape-scale variation in site susceptibility leads to the prediction that spatial, compositional, and structural patterns should emerge as the legacies of such repeat events. Two of the largest impact disturbances at Bartlett over the past century have been the hurricane of September 1938 and the ice storm of January 1998. Published research $^{70}$ and unpublished data (M. L. Smith personal communication; forest service records) indicate that moderate-to-severe tree damage sustained from both events does largely overlap over the western end of the experimental forest (Fig. 7). These same areas generally support higher levels of northern hardwood species compared to lower elevation sites at Bartlett, ${ }^{71}$ with sugar maple reaching some of the highest levels of basal area and biomass within the entire forest on these sites. These side slope sites are located generally above $350 \mathrm{~m}$ in elevation and coincide with some of the only east- and southeast-facing aspects on the landscape at Bartlett.

LVIS ground energy metrics have utility in mapping the spatial pattern of damaged forest canopy, particularly in unmanaged tracts. Relatively high values of ground energy are recorded as larger numbers of photons reach the ground in areas where canopy cover has been damaged and opened to greater light penetration. At Bartlett, only areas of recent active forest management and tracts of forest subject to the most damage from the 1998 ice storm were revealed by these higher values of measured ground energy. Once restricted to reflect only largely unmanaged forest conditions at higher elevations (above $325 \mathrm{~m}$ ), the overall correspondence of high ground energy metrics with both southern through eastern aspects and the distribution of higher levels of sugar maple biomass and basal area at Bartlett is striking. The pattern suggests the possibility that 
repeat disturbance events on southern through eastern aspects have helped shape the hardwood composition of these forests.

Where natural disturbances or environmental conditions have increased the openness of the canopy within this older, largely unmanaged forest, a relationship between volume losses to mortality and LVIS structural metrics can be established. In this situation, LVIS metrics are likely recording a structural configuration of the canopy that has been shaped by the same disturbance events, as well as stand age and growth rate, that also largely define the size and number of trees lost to partial disturbances such as the ice storm. At Bartlett, the 1998 ice storm has both significantly impacted canopy configuration and contributed to the current population of fallen trees and other downed wood. The 1999 LVIS flight captured the damage within two years of the January 1998 storm and before salvage operations were undertaken within sections of the experimental forest.

In general, the relationship found between the LVIS metrics and estimated tree mortality followed the well-established ecological pattern of taller trees (and hence often larger biomass trees) corresponding with larger amounts of stem volume losses. This trend became more noticeable as tree height began to exceed the mean value $(\sim 23 \mathrm{~m})$ seen in the forest as a whole (Table 1). Rhoads et al. ${ }^{72}$ discuss two factors, amount of decay and surface area of crown, as possible determinants in the differential susceptibility to damage seen between larger and smaller trees. Decay can weaken the mechanical properties of the wood in older (and often larger) trees while larger crowns accumulate heavier loads of ice and provide more surface area for wind stress - both factors increasing the likelihood of damage from ice or wind events. Hagen and Whitman ${ }^{73}$ have similarly noted that differences in volumes of downed dead wood among comparable forest types in Maine were being driven by the density of large living trees, with large-diameter living trees creating an ecological cascade of structure.

\section{Conclusions}

The general patterns from natural disturbances of intermediate severity reported elsewhere in New Hampshire ${ }^{74-76}$ are upheld at Bartlett, with damage from hurricane and ice storm being particularly evident on south to east facing slopes, higher elevations of the forest showing greater levels of damage, and mortality losses being dominated by beech, red spruce, and other hardwoods with little contribution from sugar maple.

The ability to examine the spatial, compositional, and structural patterns revealed by waveform lidar and hyperspectral data in conjunction with other physical landscape patterns may allow information on the characteristic distribution of these events in time and space to be more broadly recognized on the landscape. Determination and recording of such spatial patterning is critical as ecologists increasingly recognize that the legacies of natural disturbance and land-use continue to influence ecosystem structure and function for decades or even centuries into the future. ${ }^{77-79}$

\section{Acknowledgments}

Lidar data were acquired through the LVIS team in the Laser Remote Sensing Branch at NASA Goddard Space Flight Center with support from the University of Maryland, College Park. This research was also funded in part through a NASA Space Grant to the University of New Hampshire, a Switzer Environmental Fellowship, and an Earth System Science Fellowship to the first author (NASA NGT5-ESSF/03-0000-0026). This project was also supported by the National Research Initiative of the USDA Cooperative State Research, Education and Extension Service, Grant No. 2003-35101-13646 (Efficient Methods of Sampling Coarse Woody Debris) to Mark J. Ducey. Portions of this research are based upon data generated in long-term research studies on the Bartlett Experimental Forest, funded by the U.S. Department of Agriculture, Forest Service Northern Research Station. 


\section{References}

1. D. R. Foster, D. H. Knight, and J. H. Franklin, "Landscape patterns and legacies resulting from large, infrequent forest disturbances," Ecosystems 1(6), 497-510 (1998).

2. M. C. Hooper, K. Arii, and M. J. Lechowicz, "Impact of a major ice storm on an old growth hardwood forest," Can. J. Bot. 79, 70-75 (2001).

3. D. R. Foster, D. H. Knight, and J. H. Franklin, "Landscape patterns and legacies resulting from large, infrequent forest disturbances," Ecosystems 1(6), 497-510 (1998).

4. E. R. Boose, D. R. Foster, and M. Fluet, "Hurricane impacts to tropical and temperate forest landscapes," Ecol. Monogr. 64(4), 369-400 (1994).

5. D. R. Foster, "Disturbance history, community organization and vegetation dynamics of the old-growth Pisgah Forest, south-western New Hampshire, USA,” J. Ecol. 76, 105-134 (1988a).

6. D. R. Foster, "Species and stand response to catastrophic wind in central New England, USA," J. Ecol. 76,135-151 (1988b).

7. D. R. Foster and E. R. Boose, "Patterns of forest damage resulting from catastrophic wind in central New England, USA," J. Ecol. 80,79-98 (1992).

8. D. R. Peart, C. V. Cogbill, and P. A. Palmiotto, "Effects of logging history and hurricane damage on canopy structure in a northern hardwoods forest," Bull. Torrey Botan. Club 199(1), 29-38 (1992).

9. A. G. Rhoads, S. P. Hamburg, T. J. Fahey, T. G. Siccama, E. N. Hane, J. Battles, C. Cogbill, J. Randall, and G. Wilson, "Effects of an intense ice storm on the structure of a northern hardwood forest," Can. J. Forest Res. 32(10), 1763-1775 (2002).

10. J. F. Weishampel, J. B. Drake, A. Cooper, J. B. Blair, and M. Hofton, "Forest canopy recovery from the 1938 hurricane and subsequent salvage damage measured with airborne LiDAR," Remote Sens. Environ. 109, 142-153 (2007).

11. M. Schwarz, C. Steinmeier, F. Holecz, O. Stebler, and H. Wagner, "Detection of windthrow in mountainous regions with different remote sensing data and classification methods," Scand. J. Forest Res. 18, 525-536 (2003).

12. A. A. Millward and C. E. Kraft, "Physical influences of landscape on a large-extent ecological disturbance: the northeastern North American ice storm of 1998," Landscape Ecol. 19(1), 99-111 (2004).

13. J. C. Boutet, Jr. and J. F. Weishampel, "Spatial pattern analysis of pre-and post- hurricane forest canopy structure in North Carolina, USA," Landscape Ecol. 18(6), 553-559 (2003).

14. J. F. Weishampel, J. B. Drake, A. Cooper, J. B. Blair, and M. Hofton, "Forest canopy recovery from the 1938 hurricane and subsequent salvage damage measured with airborne LiDAR," Remote Sens. Environ. 109,142-153 (2007).

15. R. O. Dubayah, R. G. Knox, M. A. Hofton, J. B. Blair, and J. B. Drake, "Land surface characterization using lidar remote sensing," in Spatial Information for Land Use Management, M. J. Hill and R. J. Aspinall, Eds., pp. 25-38, Gordon and Breach, Australia (2000).

16. G. G. Parker, M. A. Lefsky, and D. J. Harding, "Light transmittance in forest canopies determined using airborne laser altimetry and in-canopy quantum measurements," Remote Sens. Environ. 76, 298-309 (2001).

17. E. R. Boose, D. R. Foster, and M. Fluet, "Hurricane impacts to tropical and temperate forest landscapes," Ecol. Monogr. 64(4), 369-400 (1994).

18. D. R. Foster, "Disturbance history, community organization and vegetation dynamics of the old-growth Pisgah Forest, south-western New Hampshire, USA," J. Ecol. 76, 105-134 (1988a).

19. D. R. Peart, C. V. Cogbill, and P. A. Palmiotto, "Effects of logging history and hurricane damage on canopy structure in a northern hardwoods forest," Bull. Torrey Botan. Club 199(1), 29-38 (1992). 
20. C. W. Lafon, D. Y. Graybeal, and K. H. Orvis, "Patterns of ice accumulation and forest disturbance during two ice storms in southwestern Virginia," Phys. Geogr. 20(2), 97-115 (1999).

21. A. A. Millward and C. E. Kraft, "Physical influences of landscape on a large-extent ecological disturbance: the northeastern North American ice storm of 1998," Landscape Ecol. 19(1), 99-111 (2004).

22. A. G. Rhoads, S. P. Hamburg, T. J. Fahey, T. G. Siccama, E. N. Hane, J. Battles, C. Cogbill, J. Randall, and G. Wilson, "Effects of an intense ice storm on the structure of a northern hardwood forest," Can. J. Forest Res. 32(10), 1763-1775 (2002).

23. C. D. Canham, M. J. Papaik, and E. F. Latty, "Interspecific variation in susceptibility to windthrow as a function of tree size and storm severity for northern temperate tree species," Can. J. Forest Res. 31(1), 1-10 (2001).

24. K. D. Woods and C. V. Cogbill, "Upland old-growth forests of Adirondack Park, New York, USA," Natural Areas Journal 14, 241-257 (1994).

25. C. D. Canham, M. J. Papaik, and E. F. Latty, "Interspecific variation in susceptibility to windthrow as a function of tree size and storm severity for northern temperate tree species," Can. J. Forest Res. 31(1), 1-10 (2001).

26. C. M. Ruffner and M. D. Abrams, "Disturbance history and stand dynamics along a topographic gradient in old-growth hemlock-northern hardwood forests of the Alleghany Plateau, USA," Nat. Areas J. 23(2), 98-113 (2003).

27. W. B. Leak, "Habitat mapping and interpretation in New England," USDA Forest Service Research Paper NE-496, 28 pp. (1982).

28. W. B. Leak, "Species composition and structure of a northern hardwood stand after 61 years of group/patch selection," North. J. Appl. Forestry 16(3), 151-153 (1999).

29. W. B. Leak and M. L. Smith, "Sixty years of management and natural disturbance in a New England forested landscape," Forest Ecol. Manage. 81, 63-73 (1996).

30. M. L. Smith, S. V. Ollinger, M. E. Martin, J. D. Aber, R. A. Hallett, and G. L. Goodale, "Direct estimation of aboveground forest productivity through hyperspectral remote sensing of canopy nitrogen," Ecol. Appl. 12, 1286-1302 (2002).

31. J. E. Anderson, M. E. Martin, M. L. Smith, R. O. Dubayah, M. A. Hofton, P. Hyde, B. Peterson, J. B. Blair, and R. Knox, "The use of waveform lidar to measure northern temperate mixed conifer and deciduous forest structure in New Hampshire," Remote Sens. Environ. 105(3), 248-261 (2006).

32. J. E. Anderson, L. Plourde, M. E. Martin, R. Braswell, M. L. Smith, R. Dubayah, M. Hofton, and J. B. Blair, "Integrating Waveform Lidar with Hyperspectral Imagery for Inventory of a Northern Temperate Forest," Remote Sens. Environ. 112(4), 1856-1870 (2008).

33. W. B. Leak and M. L. Smith, "Sixty years of management and natural disturbance in a New England forested landscape," Forest Ecol. Manage. 81, 63-73 (1996).

34. P. A. Ingraham, "Detecting rich mesic forest: A remote sensing and geographic information systems approach," MS Thesis, University of New Hampshire (2004).

35. J. C. Jenkins, D. C. Chojnacky, L. S. Heath, and R. A. Birdsey, "Comprehensive database of diameter-based biomass regressions for North American tree species," USDA Forest Service General Technical Report NE-319, 45 pp. (2004).

36. J. B. Blair, D. L. Rabine, and M. A. Hofton, "The Laser Vegetation Imaging Sensor (LVIS): A medium- altitude, digitisation-only, airborne laser altimeter for mapping vegetation and topography," ISPRS J. Photogramm. Remote Sens. 54, 115-122 (1999).

37. J. B. Blair, D. L. Rabine, and M. A. Hofton, "The Laser Vegetation Imaging Sensor (LVIS): A medium-altitude, digitisation-only, airborne laser altimeter for mapping vegetation and topography," ISPRS J. Photogramm. Remote Sens. 54, 115-122 (1999).

38. P. Hyde, R. Dubayah, B. Peterson, J. B. Blair, M. Hofton, C. Hunsaker, R. Knox, and W. Walker, "Mapping forest structure for wildlife habitat analysis using waveform lidar: Validation of montane ecosystems," Remote Sens. Environ. 96, 427-437 (2005). 
Anderson et al.: Use of waveform lidar and hyperspectral sensors to assess selected...

39. J. E. Anderson, M. E. Martin, M. L. Smith, R. O. Dubayah, M. A. Hofton, P. Hyde, B. Peterson, J. B. Blair, and R. Knox, "The use of waveform lidar to measure northern temperate mixed conifer and deciduous forest structure in New Hampshire," Remote Sens. Environ. 105(3), 248-261(2006).

40. J. B. Drake, R. O. Dubayah, D. B. Clark, R. G. Knox, J. B. Blair, M. A. Hofton, R. L. Chazdon, J. F. Weishampel and S. D. Prince, "Estimation of tropical forest structural characteristics using large-footprint lidar," Remote Sens. Environ. 79, 305-319 (2002).

41. M. A. Hofton, J. B. Minster, and J. B. Blair, "Decomposition of laser altimeter waveforms," IEEE Trans. Geosci. Remote Sens. 38, 1989-1996 (2000).

42. W. G. Warren, P. F. Olsen, "A line intersect technique for assuming logging waste," Forest Science 10, 267-276 (1964).

43. C. E. Van Wagner, "The line intercept method in forest fuel sampling," Forest Sci. 15, 20-26 (1968).

44. L. Kaiser, "Unbiased estimation in line-intercept sampling," Biometrics 39, 965-976 (1983).

45. C. Pyle, M. M. Brown, "A rapid system of decay classification for hardwood logs of the eastern deciduous forest floor," J. Torrey Botan. Club 125, 237-245 (1998).

46. C. Pyle and M. M. Brown, "Heterogeneity of wood decay classes within hardwood logs," Forest Ecol. Manage. 114, 253-259 (1999).

47. A. J. Fast, M. J. Ducey, J. H. Gove, and W. B. Leak, "Dating tree mortality using log decay in the White Mountains of New Hampshire," North. J. Appl. Forestry 25(3), 154-157 (2008).

48. W. B. Leak and D. S. Solomon, "Influence of residual stand density on regeneration of northern hardwoods," USDA Forest Service Northeastern Forest Experiment Research Paper NE-310 (1975).

49. D. A. Solomon, "Growth rates of northern hardwoods under uneven-age management," The Northern Logger 25(8), 18-38 (1977a).

50. D. A. Solomon, "The influence of stand density and structure on growth of northern hardwoods in New England," USDA Forest Service Northeastern Station Research Paper NE-362, 13 pp. (1977b).

51. A. J. Fast, M. J. Ducey, J. H. Gove, and W. B. Leak, "Dating tree mortality using log decay in the White Mountains of New Hampshire," North. J. Appl. Forestry 25(3), 154-157 (2008).

52. T. G. Honer, "Standard volume tables and merchantable conversion factors for the commercial tree species of central and eastern Canada," Canadian Department of Forestry, Rural Development, Forest Management Research and Service Institute Information Report FMR-X-5 (1967).

53. L. Kaiser, "Unbiased estimation in line-intercept sampling," Biometrics 39, 965-976 (1983).

54. G. Vane and A. F. H. Goetz, "Terrestrial imaging spectroscopy," Remote Sens. Environ. 24, 1-29 (1988).

55. B. C. Gao, K. B. Heidebrecht, and A. F. H. Goetz, Atmospheric Removal Program (ATREM) User's Guide, Center for the Study of Earth from Space, Cooperative Institute for Research in Environmental Sciences, University of Colorado, Boulder, (1992).

56. A. A. Green, M. Berman, P. Switzer, and M. D. Craig, "A transformation for ordering multispectral data in terms of image quality with implications for noise removal," IEEE Trans. Geosci. Remote Sens. 26, 65-74 (1988).

57. J. W. Boardman and F. A. Kruse, "Automated spectral analysis: A geological example using AVIRIS data, north Grapevine Mountains, Nevada," Proceedings, ERIM Tenth Thematic Conference on Geologic Remote Sensing, Environmental Research Institute of Michigan, Ann Arbor, MI, pp. I407-I418 (1994).

58. A. J. Elmore, J. F. Mustard, S. J. Manning, and D. B. Lobell, "Quantifying vegetation change in semiarid environments: Precision and accuracy of spectral mixture analysis and the Normalized Difference Vegetation Index," Remote Sens. Environ., 73, 87-102 (2000). 
59. C. Small, "Estimation of urban vegetation abundance by spectral mixture analysis," Remote Sens. Environ. 22, 1305-1334 (2001).

60. J. H. Pontius, R. A. Hallett, and M. E. Martin, "Using AVIRIS to assess hemlock abundance and early decline in the Catskills, New York," Remote Sens. Environ., 97, 163-173 (2005).

61. X. Miao, P. Gong, S. Swope, R. Pu, R. Carruthers, G. L. Anderson, J. S. Heaton, and C. R. Tracy, "Estimation of yellow star thistle abundance through CASI-2 hyperspectral imagery using linear spectral mixture models," Remote Sens. Environ., 101, 329-341 (2006).

62. L. Plourde, S. V. Ollinger, M. L. Smith, and M. E. Martin, "Species classification for a northern temperate forest using spectral unmixing of hyperspectral remote sensing imagery," Photogramm. Eng. Remote Sens. 73(7), 829-840 (2007).

63. J. W. Boardman, "Leveraging the high dimensionality of AVIRIS data for improved subpixel target unmixing and rejection of false positives: mixture tuned matched filtering," Proceedings of the Seventh JPL Airborne Geoscience Workshop, JPL Publication 97-1, Pasadena, CA: NASA Jet Propulsion Laboratory, pp. 55-56 (1998).

64. A. P. Williams and A. R. Hunt, Jr., "Estimation of leafy spurge cover from hyperspectral imagery using mixture tuned matched filtering," Remote Sens. Environ., 82, 446-456, (2002).

65. P. Hyde, R. Dubayah, B. Peterson, J. B. Blair, M. Hofton, C. Hunsaker, R. Knox, and W. Walker, "Mapping forest structure for wildlife habitat analysis using waveform lidar: Validation of mantane ecosystems," Remote Sens. Environ. 96, 427-437 (2005).

66. S. S. Shapiro and M. B. Wilk, "An analysis of variance test for normality (complete samples)," Biometrika 52(3-4), 591-611(1965).

67. H. Mark and J. Workman, Statistics in Spectroscopy, Academic Press, San Diego, CA (1991).

68. T. Hastie, R. Tibshirani, and J. Friedman, The Elements of Statistical Learning: Data Mining, Inference and Prediction, Springer-Verlag, New York (2001).

69. D. R. Foster, D. H. Knight, and J. H. Franklin, "Landscape patterns and legacies resulting from large, infrequent forest disturbances," Ecosystems 1(6), 497-510 (1998).

70. A. J. Fast, M. J. Ducey, J. H. Gove, and W. B. Leak, "Dating tree mortality using log decay in the White Mountains of New Hampshire," North. J. Appl. Forestry 25(3), 154-157 (2008).

71. L. Plourde, S. V. Ollinger, M. L. Smith, and M. E. Martin, "Species classification for a northern temperate forest using spectral unmixing of hyperspectral remote sensing imagery," Photogramm. Eng. Remote Sens. 73(7), 829-840 (2007).

72. A. G. Rhoads, S. P. Hamburg, T. J. Fahey, T. G. Siccama, E. N. Hane, J. Battles, C. Cogbill, J. Randall, and G. Wilson, "Effects of an intense ice storm on the structure of a northern hardwood forest," Can. J. Forest Res. 32(10), 1763-1775 (2002).

73. J. M. Hagen and A. A. Whitman, "A comparison of forest structure in old-growth, even-aged, and uneven-aged forest types in Maine," in Forest Structure: A Multilayered Conversation. Proceedings of the Forest Information Exchange. J. M. Hagan, Ed., pp. 72-75, Manomet Center for Conservation Sciences, Brunswick, ME, (2001).

74. D. R. Foster, "Disturbance history, community organization and vegetation dynamics of the old-growth Pisgah Forest, south-western New Hampshire, USA," J. Ecol. 76, 105-134 (1988a).

75. A. G. Rhoads, S. P. Hamburg, T. J. Fahey, T. G. Siccama, E. N. Hane, J. Battles, C. Cogbill, J. Randall, and G. Wilson, "Effects of an intense ice storm on the structure of a northern hardwood forest," Can. J. Forest Res. 32(10), 1763-1775 (2002).

76. D. R. Peart, C. V. Cogbill, and P. A. Palmiotto, "Effects of logging history and hurricane damage on canopy structure in a northern hardwoods forest," Bull. Torrey Botan. Club 199(1), 29-38 (1992).

77. D. R. Foster, D. H. Knight, and J. H. Franklin, "Landscape patterns and legacies resulting from large, infrequent forest disturbances," Ecosystems 1(6), 497-510 (1998). 
Anderson et al.: Use of waveform lidar and hyperspectral sensors to assess selected...

78. D. R. Foster, F. Swanson, J. Aber, I. Burke, N. Brokaw, D. Tilman, and A. Knapp, “The importance of land-use legacies to ecology and conservation," Bioscience 53(1), 77-88 (2003).

79. J. F. Weishampel, J. B. Drake, A. Cooper, J. B. Blair, and M. Hofton, "Forest canopy recovery from the 1938 hurricane and subsequent salvage damage measured with airborne LiDAR," Remote Sens. Environ. 109, 142-153 (2007).

Biographies and photographs of the authors not available. 